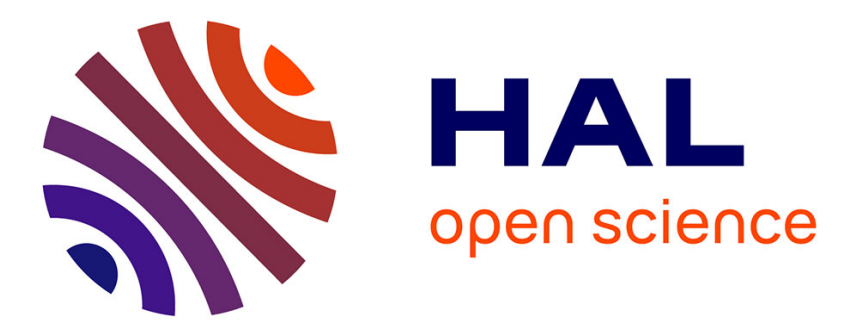

\title{
Molecular Sieving and Current Rectification Properties of Thin Organic Films
}

Yara Aceta, Jean-François Bergamini, Corinne Lagrost, Philippe Hapiot, Yann Leroux

\section{- To cite this version:}

Yara Aceta, Jean-François Bergamini, Corinne Lagrost, Philippe Hapiot, Yann Leroux. Molecular Sieving and Current Rectification Properties of Thin Organic Films. Langmuir, 2018, 34 (7), pp.24102419. 10.1021/acs.langmuir.7b03518 . hal-01737384

HAL Id: hal-01737384 https://hal-univ-rennes1.archives-ouvertes.fr/hal-01737384

Submitted on 18 May 2018

HAL is a multi-disciplinary open access archive for the deposit and dissemination of scientific research documents, whether they are published or not. The documents may come from teaching and research institutions in France or abroad, or from public or private research centers.
L'archive ouverte pluridisciplinaire $\mathbf{H A L}$, est destinée au dépôt et à la diffusion de documents scientifiques de niveau recherche, publiés ou non, émanant des établissements d'enseignement et de recherche français ou étrangers, des laboratoires publics ou privés. 


\title{
Molecular Sieving and Current Rectification Properties of Thin Organic Films.
}

\author{
Yara Aceta, Jean-Francois Bergamini, Corinne Lagrost, Philippe Hapiot and Yann R. Leroux* \\ Univ Rennes, CNRS, ISCR - UMR 6226, F-35000 Rennes, France.
}

\begin{abstract}
.
In a purpose of preparing well-organized functional surfaces, carbon and gold substrates were modified using the electro-reduction of a tetrahedral-shape pre-organized tetra-aryldiazonium salt leading to the deposition of ultrathin organic films. Characterization of the modified surfaces has been performed using cyclic voltammetry (CV), X-Ray Photoelectron spectroscopy (XPS), Infrared absorption spectroscopy (IR), ellipsometry, Atomic Force Microscopy (AFM) and contact angle measurements. The specific design of the tetra-aryldiazonium salts lead to an intrinsic structuring of the resulting organic films, allowing molecular sieving and current rectification properties towards redox probes in solution.
\end{abstract}




\section{Introduction.}

The (electro-) reduction of aryl diazonium salts ${ }^{1}$ is nowadays a common technique used to functionalize many surfaces. The procedure leads to the formation of aryl radicals in solution by loss of nitrogen and they are highly reactive species. When aryl radicals are produced in the close vicinity of an electrode, they could rapidly add to it leading to surfaces modified by covalently bonded organic films with varying thicknesses from monolayers ${ }^{2,3,4,5,6}$ to thicker films $(5 \mathrm{~nm}<\mathrm{x}<100 \mathrm{~nm})^{7,8}$ and even up to few micrometers. ${ }^{9}$ Conductors and semiconductors surfaces could be easily modified by electrochemically-induced aryl diazonium reduction leading to a fast modification (seconds-minutes) of the substrate. ${ }^{10}$ Furthermore, insulators ${ }^{11}$ could also be modified by this technique when adding chemical reductants ${ }^{12}$ in solution, by the formation of diazoates $^{13}$ or by spontaneous grafting ${ }^{14}$ which makes this technique very versatile. Aryl diazonium salts (electro-) reduction was proposed for a wide range of applications, ranging from corrosion protection, ${ }^{15}$ active plasmonic devices, ${ }^{16}$ to super-capacitors ${ }^{17}$ and molecular diodes. $^{18,19}$

Devices allowing the control of molecular transport and electron transfer such as molecular sieves and rectifiers are of high interest. Electrochemical devices with current rectification properties have been originally reported by Murray et al. ${ }^{20}$ Briefly, electrochemical current rectifiers $(\mathrm{ECR})$ consist in surfaces functionalized by redox species allowing unidirectional current of solution-phase redox probe to pass through. ECR could be realized using surfaces functionalized through a wide range of techniques including Self-Assembled Monolayers (SAMs), ${ }^{21}$ coordination-based molecular assemblies ${ }^{22}$ or biological interfaces ${ }^{23}$ to quote a few. More complex systems as redox-active dendrimers immobilized onto SAMs deposited on gold surfaces have also been reported to present electrochemical current rectification via mediated 
electron transfer across the modified surfaces. ${ }^{24,25}$ Despite the versatility and robustness of the procedure, only very few examples of ECR fabricated by the electro-reduction of aryl diazonium salts were demonstrated. Indeed, the reduction of classical aryl diazonium ions, as the most commonly used $p$-nitrophenyl diazonium ion, leads to the formation of multilayered dendritic insulating films which limits the electron transfer from the substrate to solution-phase redox probes. However, the reduction of specifically designed aryl diazonium salts, incorporating redox unit as thiophene for example was demonstrated by Lacroix and coworkers ${ }^{26}$ to yield organic films having ECR activities towards redox probes in solutions.

The design of molecular sieves attracts attention of many research groups these days as they could find utility in tomorrow applications as water desalination, ${ }^{27}$ gas separation ${ }^{28}$ or acting as membrane in fuel cells. ${ }^{29}$ Molecular sieves can be realized using many different materials as for example vertically aligned mesoporous silica films, ${ }^{30}$ porous covalent-organic-framework, ${ }^{31}$ metallopolymeric films, ${ }^{32}$ graphene-based ${ }^{33}$ or biological-based materials. ${ }^{34}$ As stated before, the reduction of aryl diazonium salts yields dendritic multilayered films, i.e. unorganized films. Hence the intrinsic nature of these films is not suitable for molecular sieving. Regarding this specific application, the use of aryl diazonium salts reduction is limited to the functionalization of already existing molecular sieves for tuning their pore sizes ${ }^{35}$ and/or their chemical nature. ${ }^{36}$

In this work, we report the formation of ultrathin organic films through the electro-reduction of aryl diazonium salts having both electrochemical current rectification properties and molecular sieving properties. The characterization of these films has been performed by Cyclic Voltammetry (CV), X-Ray Photoelectron spectroscopy (XPS), Infrared absorption spectroscopy (IR), ellipsometry, Atomic Force Microscopy (AFM) and contact angle measurements. Results reveal that both specific properties are due to the organization of the deposited thin organic films. 


\section{Experimental.}

\subsection{Materials}

All commercially available reagents were used as received.

Tetrakis(4-phenyldiazonium tetrafluoroborate)methane $\mathbf{C}\left(\mathbf{A r N}_{2}{ }^{+}\right)_{4}$ :

Tetrakis(4-aminophenyl)methane $(0.5 \mathrm{~g}, 1.3 \mathrm{mmol}, 1 \mathrm{eq})$ was added to a mixture of $10 \mathrm{~mL}$ acetone and $30 \mathrm{~mL}$ of aqueous $\mathrm{HBF}_{4}(33 \%)$ and stirred for $10 \mathrm{~min}$. After cooling with an ice bath, sodium nitrite $(0.545 \mathrm{~g}, 7.9 \mathrm{mmol}, 6 \mathrm{eq})$ dissolved in the minimum amount of water was added dropwise to the solution under stirring. The reaction mixture was stirred 1 hour at $0^{\circ} \mathrm{C}$, then filtered. The precipitate was copiously washed with water, methanol and diethyl ether. Recrystallization of the diazonium salt was performed in acetonitrile:diethyl ether (1:1), yielding $0.745 \mathrm{~g}$ of $\mathbf{C}\left(\mathrm{ArN}_{\mathbf{2}}{ }^{+}\right)_{\mathbf{4}}(73 \%) .{ }^{1} \mathrm{H}-\mathrm{NMR}\left(300 \mathrm{MHz}, \mathrm{CD}_{3} \mathrm{CN}\right): \delta=8.53(\mathrm{~d}, 8 \mathrm{H}, \mathrm{J}=9.30 \mathrm{~Hz}), 7.88$ $(\mathrm{d}, 8 \mathrm{H}, \mathrm{J}=9.06 \mathrm{~Hz}), \mathrm{ppm} . \mathrm{IR}(\mathrm{KBr}) v=2285 \mathrm{~cm}^{-1}\left(\mathrm{~N} \equiv \mathrm{N}^{+}\right)$.

Scheme 1. Preparation of the tetrakis(4-phenyldiazonium tetrafluoroborate)methane $\mathbf{C}\left(\mathbf{A r N}_{2}{ }^{+}\right)_{4}$.

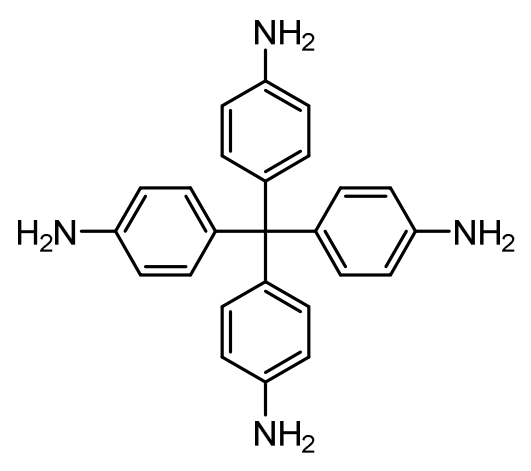

tetrakis(4-aminophenyl)methane

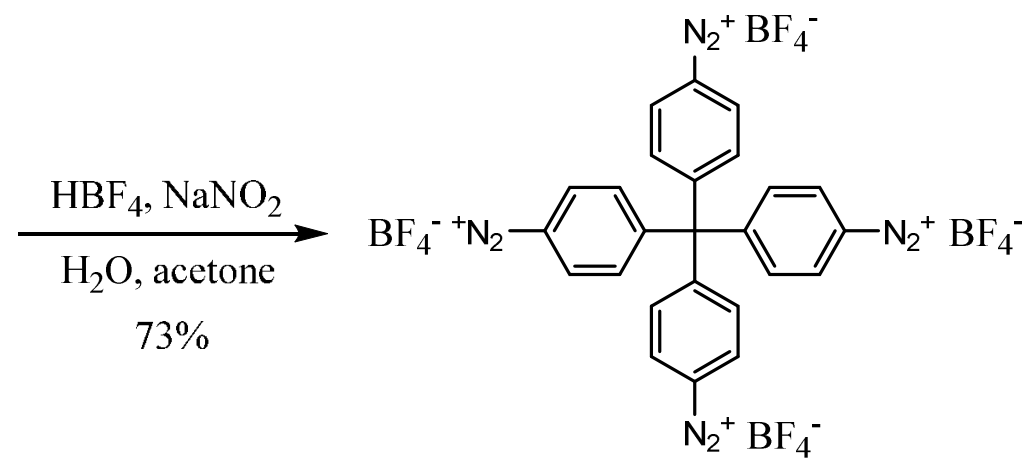

tetrakis(4-phenyldiazonium)methane 


\section{1,1'-Di(methylphenyl)ferrocene (PhMe) $)_{2} \mathbf{F c}$ :}

Benzoïc acid (787 mg, $6.4 \mathrm{mmol}, 2.4 \mathrm{eq})$ was added to a dichloromethane $\left(\mathrm{CH}_{2} \mathrm{Cl}_{2}\right)$ solution (5 $\mathrm{mL}$ ) of oxalyl chloride $(5 \mathrm{~mL}, 58 \mathrm{mmol})$ and stirred 24 hours at room temperature. The following day, excess of oxalyl chloride was evaporated by vacuum and the resulting chlorine benzoate was dissolved in $10 \mathrm{~mL}$ anhydrous $\mathrm{CH}_{2} \mathrm{Cl}_{2}$ under Argon. Separately, ferrocene $(0.5 \mathrm{~g}, 2.7 \mathrm{mmol}$, $1 \mathrm{eq})$ and $\mathrm{AlCl}_{3}\left(896 \mathrm{mg}, 6.7 \mathrm{mmol}, 2.5 \mathrm{eq}\right.$ ) were dissolved into $20 \mathrm{~mL}$ anhydrous $\mathrm{CH}_{2} \mathrm{Cl}_{2}$ and cooled to $0^{\circ} \mathrm{C}$. The chlorine benzoate solution was then added dropwise over 1 hour in the ferrocene solution. The mixture was warmed to room temperature and stirred overnight. The resulting mixture was poured into water and extracted with ethyl acetate. The combined organic extracts were washed with brine, dried $\left(\mathrm{MgSO}_{4}\right)$ and concentrated under reduced pressure. Purification was performed on column chromatography using silica gel and hexane: $\mathrm{CH}_{2} \mathrm{Cl}_{2}(1: 1)$ to pure $\mathrm{CH}_{2} \mathrm{Cl}_{2}$ as eluent. Both mono- and di-substituted ferrocene derivatives were obtained. 11'-di(benzoyl)ferrocene was obtained in $34 \%$ yield $(360 \mathrm{mg}) .{ }^{1} \mathrm{H}$ NMR $\left(300 \mathrm{MHz}, \mathrm{CDCl}_{3}\right): \delta$ (ppm): $4.58(\mathrm{t}, 4 \mathrm{H}, \mathrm{J}=1.82 \mathrm{~Hz}), 4.92(\mathrm{t}, 4 \mathrm{H}, \mathrm{J}=1.82 \mathrm{~Hz}), 7.42(\mathrm{t}, 4 \mathrm{H}, \mathrm{J}=7.5 \mathrm{~Hz}), 7.54(\mathrm{t}, 2 \mathrm{H}, \mathrm{J}$ $=7.50 \mathrm{~Hz}), 7.78(\mathrm{~d}, 4 \mathrm{H}, \mathrm{J}=7.70 \mathrm{~Hz})$.

In a flask equipped with a reflux condenser, $\mathrm{AlCl}_{3}(8.36 \mathrm{~g}, 63.4 \mathrm{mmol})$ was dissolved in $20 \mathrm{~mL}$ of $\mathrm{Et}_{2} \mathrm{O}$. $\mathrm{LiAlH}_{4}$ (4M solution) was then added dropwise. 1-1'-di(benzoyl)ferrocene (360 mg, $0.91 \mathrm{mmol}, 1 \mathrm{eq}$ ) was dissolved in $10 \mathrm{~mL} \mathrm{CH}_{2} \mathrm{Cl}_{2}$ and added dropwise into the first solution and stirred 1 hour. The solution was slowly quenched with water and $1 \mathrm{M} \mathrm{HCl}$ solution was added. The resulting mixture was extracted with $\mathrm{CH}_{2} \mathrm{Cl}_{2}$. The combined organic extracts were washed with brine, dried $\left(\mathrm{MgSO}_{4}\right)$ and concentrated. Purification was performed on column chromatography using silica gel and hexane: $\mathrm{CH}_{2} \mathrm{Cl}_{2}(9: 1)$ as eluent to obtain the desired 
compound in $73 \%$ yield $(245 \mathrm{mg})$ as an orange powder. ${ }^{1} \mathrm{H} \mathrm{NMR}\left(300 \mathrm{MHz}, \mathrm{CDCl}_{3}\right): \delta(\mathrm{ppm})$ :

$3.62(\mathrm{bs}, 4 \mathrm{H}), 4.10(\mathrm{bs}, 8 \mathrm{H}), 7.17(\mathrm{t}, 6 \mathrm{H}, \mathrm{J}=7.60 \mathrm{~Hz}), 7.26(\mathrm{t}, 4 \mathrm{H}, \mathrm{J}=7.08 \mathrm{~Hz})$.

1-(Biphenylethynyl)ferrocene $\mathbf{P h}_{2} \mathbf{E F c}$ :

To a stirring solution of ethynylferrocene $(100 \mathrm{mg}, 0.446 \mathrm{mmol}, 1 \mathrm{eq})$ dissolved in a mixture of THF $(10 \mathrm{~mL})$ and diisopropylamine $(10 \mathrm{~mL})$ was added 4-iodobiphenyl (147 $\mathrm{mg}, 0.524$ mmol, 1.1 eq). After degassing with Argon 15 min, tetrakis(triphenylphosphine)palladium(0) (28 $\mathrm{mg}, 5 \mathrm{~mol} \%$ ) was added in one portion. After $5 \mathrm{~min}$, copper(I) iodide (5 mg, $5 \mathrm{~mol} \%$ ) was added and the solution was stirred at room temperature overnight under Ar. The reaction mixture was filtered and washed with hexane. The combined organic phase was washed with $\mathrm{NH}_{4} \mathrm{Cl}$, brine and water and dried with $\mathrm{MgSO}_{4}$. Purification was performed on column chromatography using silica gel and hexane: $\mathrm{CH}_{2} \mathrm{Cl}_{2}(9: 1)$ as eluent to obtain the desired compound in $90 \%$ yield (156 $\mathrm{mg})$ as a red powder. ${ }^{1} \mathrm{H} \mathrm{RMN}\left(\mathrm{CDCl}_{3}\right): \delta(\mathrm{ppm}): 4.23-4.32(\mathrm{~m}, 7 \mathrm{H}), 4.50-4.56(\mathrm{~m}, 2 \mathrm{H}), 7.36(\mathrm{t}$, $1 \mathrm{H}, \mathrm{J}=7.30 \mathrm{~Hz}), 7.45(\mathrm{t}, 2 \mathrm{H}, \mathrm{J}=7.30 \mathrm{~Hz}), 7.60(\mathrm{t}, 6 \mathrm{H}, \mathrm{J}=7.78 \mathrm{~Hz})$.

\subsection{Electrochemical Experiments.}

Electrochemical measurements were performed using a conventional three-electrode system comprising a $1.8 \mathrm{~mm}$ gold (Au) and 3mm glassy carbon (GC) disk electrodes (IJ Cambria) as working electrode, a platinum wire as the auxiliary electrode, and a SCE electrode (Metrohm) as reference. The potentiostat was an Autolab PGSTAT 302N (Metrohm). The Au/GC electrodes were polished successively with $1.0,0.3$, and $0.05 \mu \mathrm{m}$ alumina paste and thoroughly rinsed. Considering AFM, XPS, ellipsometry and contact angle measurements, all these experiments need to be performed on flat surfaces. Hence, we used Pyrolized Photoresist Films (PPF), which present similar reactivity than GC and low roughness and gold substrate on silicon wafer 
purchased from Aldrich. The preparation of PPF follows the previously described methods. ${ }^{37}$ The PPF substrates were square surfaces of $15 \mathrm{~mm}^{2}$. The gold substrates were thoroughly cleaned using Piranha solution, ultrapure water and acetone before surface functionalization.

Caution! Piranha solution is a very strong oxidant and is extremely dangerous to work with; it should be handled very carefully.

\subsection{Preparation of the modified substrates.}

Surface modifications were performed in a saturated solution $\left(<5.10^{-4} \mathrm{~mol} \mathrm{~L}^{-1}\right)$ of $\mathbf{C}\left(\mathbf{A r N}_{2}{ }^{+}\right)_{4}$ $+0.1 \mathrm{~mol} \mathrm{~L}^{-1} n \mathrm{Bu}_{4} \mathrm{NPF}_{6}$ in acetonitrile $(\mathrm{MeCN})$ using repetitive cyclic voltammetry (scan rate 50 $\mathrm{mV} \mathrm{s}^{-1}$, five cycles between +0.6 and $-0.8 \mathrm{~V}$ vs SCE) or fixed potential amperometry deposition for $300 \mathrm{~s}$ at $-0.8 \mathrm{~V}$ vs SCE. The modified electrodes were rinsed with copious amount of $\mathrm{MeCN}$ and acetone, stirred 20 min in THF solution and dried under argon.

\subsection{Contact angle measurements.}

The static contact angle measurements were performed on an easy drop goniometer (Krüss) with a drop volume of $2 \mu \mathrm{L}$ ultrapure water. All given values in the text are average of measurements on six different spots and on two different substrates. The contact angles were determined using a tangent 2 model.

\subsection{Ellipsometry.}

The thicknesses of the organic films were measured using a spectroscopic ellipsometer $\alpha \mathrm{SE}$ (J.A. Woollam, Co.) using a model-based analysis approach. Prior to modification with the aryldiazonium molecule, the SE data of the bare substrate were registered to build a substrate 
optical model which represents the nominal structure of the non-modified material; the refractive index (n) and the extinction coefficient (k) found were 0.4 and 3.5 for gold, and 2.4 and 1.1 for bare PPF electrodes respectively. This substrate model was used after modification to establish the contribution of the substrate to the SE experimental data and thus, estimate the thickness of the organic layer according to the Cauchy model. Finally the goodness of the fit was quantified by the Mean Squared Error (MSE) to validate our results. In all cases the fitting reproduced the structures and features of the SE experimental data (MSE values below 4). All the values given in the text are average values of ten measurements performed on three different substrates.

\subsection{X-Ray Photoelectron spectroscopy (XPS).}

X-ray photoelectron spectroscopy data have been collected using a Kratos Axis Nova spectrometer using the $\mathrm{Al} \mathrm{K} \alpha \mathrm{X}$-ray source working at $1486.6 \mathrm{eV}$ and using a spot size of $0.7 \times 0.3 \mathrm{~mm}^{2}$. Survey spectra $(0-1000 \mathrm{eV})$ were acquired with an analyzer pass energy of $160 \mathrm{eV}$ (0.5 eV/step); high resolution spectra used a pass energy of $40 \mathrm{eV}(0.1 \mathrm{eV} / \mathrm{step})$. Binding energies were referenced to $\mathrm{C} 1 \mathrm{~s}$ peak at $285 \mathrm{eV}$. The core level spectra were peak-fitted using the CasaXPS software, Ltd., version 2.3.18.

\subsection{Atomic Force Microscopy (AFM).}

Atomic force microscopy (AFM) experiments have been performed on a NT-MDT Ntegra microscope. Topographic images were obtained in semi-contact mode using ACTA tips (AppNano Inc.) for which the resonance frequency is around $300 \mathrm{kHz}$. Scratching experiments were performed with the same tips in order to estimate the thickness of the organic layers according to the McCreery AFM "scratch" procedure. ${ }^{38}$ The term "AFM scratching" is used here 
to describe intentional damage to a modification layer on a relatively hard substrate. These experiments were obtained by scanning the surface in contact mode on a $500 \times 500 \mathrm{~nm}$ square with a force setpoint sufficient to remove the organic layer. After scratching, the damaged surface imaged in semi-contact mode presented a square-shaped zone surrounded by swept amounts of matter. The images were treated by Gwyddion open-source software. ${ }^{39}$ The heights of organic layers were extracted from the depths of the scratched zones averaged on different profiles. Scratching experiments were also performed on bare Au and PPF surfaces to evaluate the eventual damaging of the substrate. In this case, the heights of the scratched zones were measured and were subtracted to those obtained on the modified surfaces, in order to obtain corrected organic layer heights taking into account the substrate damaging.

\subsection{Density Functional Theory (DFT) calculations.}

The conformation of all ferrocene derivatives were optimized using density functional theory (DFT) calculations at the B3LYP/6-31G* level using the Gaussian 09 Revision B.01 package with the default parameters. ${ }^{40}$ The molecular volume is computed as the volume inside a contour of 0.001 electron/bohr3 using a Monte-Carlo method of integration and the SCF density. The number of points per bohr3 is 100 with a cutoff $=10-4$ and used with the "Vol=Tight" option for a better accuracy that is better than $10 \%{ }^{41}$ 
2. Results and discussions.

Characterization of the deposited organic thin films. The tetrakis(4-phenyldiazonium tetrafluoroborate)methane $\mathbf{C}\left(\mathbf{A r N}_{2}{ }^{+}\right)_{4}$ (Figure 1a) was synthesized in one step procedure from commercially available tetrakis(4-aminophenyl)methane under classic diazotization conditions and obtained in good yield (see Experimental section). The electrochemical behavior of $\mathbf{C}\left(\mathrm{ArN}_{2}{ }^{+}\right)_{4}$ was examined by cyclic voltammetry $(\mathrm{CV})$ on a glassy carbon (GC) electrode (Figure 1b). The electrochemical behavior of $\mathbf{C}\left(\mathbf{A r N}_{2}{ }^{+}\right)_{4}$ is characterized by a single reduction peak at $0.08 \mathrm{~V}$ vs SCE, indicating that all diazonium functions are reduced at the same potential. This behavior can be explained by the S4 symmetry of the molecule and the lack of electronic coupling between each diazonium function in an equivalent chemical environment. Furthermore, there is no oxidation peak associated to the reduction one as generally observed for diazonium ion reduction. This corresponds to the cleavage of $\mathrm{N}_{2}$ groups concomitant with the formation of aryl radicals. A strong inhibition of the electrochemical signal is observed after the first cycle and no more electro-activity of solution-phase species is observed. This is characteristic of the deposition of an insulating organic film, leading to a blocked electrode. ${ }^{42}$ The electrochemical behavior of $\mathbf{C}\left(\mathbf{A r N}_{2}{ }^{+}\right)_{4}$ was also examined on gold surfaces by CV. (Figure S1) Similar observations and conclusions can be drawn, excepting that multiple reduction peaks (two) are observed during the first scan. Multi-peaks in aryl diazonium electro-reduction on gold have already been observed previously and have been attributed to the reduction of aryl diazonium ions on different crystallographic facets of polycrystalline gold electrodes. ${ }^{43}$ 
a)

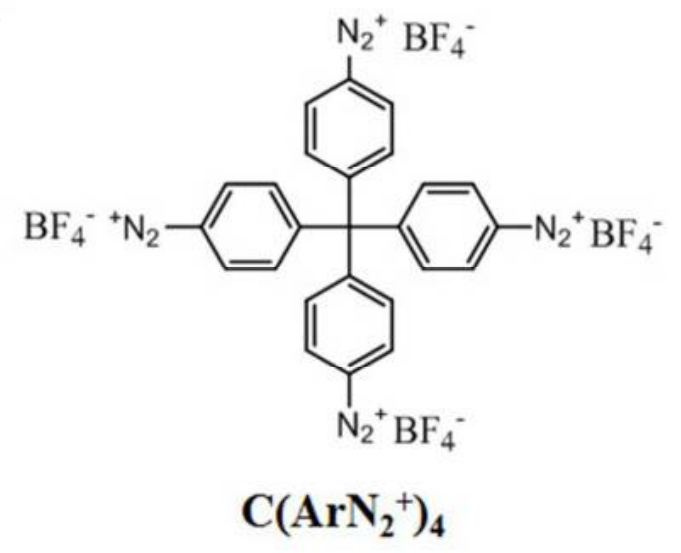

b)

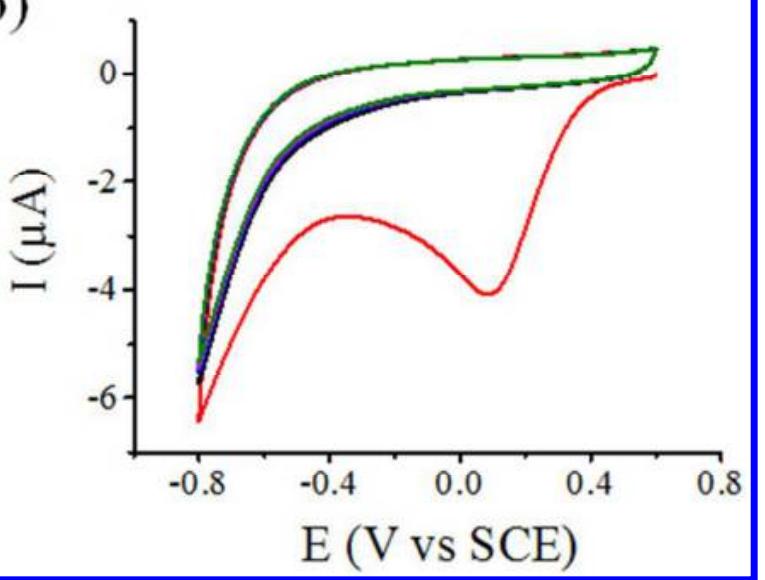

Figure 1. a) Schematic representation of tetrakis(4-phenyldiazonium tetrafluoroborate)methane $\mathbf{C}\left(\mathbf{A r N}_{2}{ }^{+}\right)_{4}$. b) Electrochemical behavior of $\mathbf{C}\left(\mathrm{ArN}_{2}{ }^{+}\right)_{4}$ in an acetonitrile solution containing 0.1 mol L-1 of tetrabutylammonium hexafluorophosphate $\left(n \mathrm{Bu}_{4} \mathrm{NPF}_{6}\right)$ on glassy carbon electrode.

Both CV and fixed potential amperometry deposition procedures were used to functionalize carbon and gold surfaces. Using a fresh saturated $\left(<510^{-4} \mathrm{~mol} \mathrm{~L}^{-1}\right)$ acetonitrile solution of $\mathbf{C}\left(\mathbf{A r N}_{2}{ }^{+}\right)_{4}$ containing $0.1 \mathrm{~mol} \mathrm{~L}^{-1}$ of tetrabutylammonium hexafluorophosphate $\left(n \mathrm{Bu}_{4} \mathrm{NPF}_{6}\right)$, gold and carbon surfaces were modified either by cyclic voltammetry with 5 cycles by sweeping the potential between $0.6 \mathrm{~V}$ and $-0.8 \mathrm{~V}$ vs SCE at $50 \mathrm{mV} \mathrm{s}^{-1}$ or by fixed potential amperometry at $-0.8 \mathrm{~V}$ vs SCE during 300s. First, Atomic Force Microscopy (AFM) experiments were performed on modified gold and carbon substrates to characterize the deposited organic films. The organic layers appear homogenous and compact without any defects or pinholes highlighting the uniformity of the deposition on gold and carbon materials (Figure S2). The roughness of the deposited organic layer measured on gold and carbon substrate are $0.510 \mathrm{~nm}$ and $0.192 \mathrm{~nm}$ respectively (RMS value), and are similar to the roughness RMS value of the bare materials. 
In order to characterize the deposited organic films, contact angle measurements were performed on both gold and carbon substrates. As expected for a gold substrate functionalized by an organic thin film, its hydrophobicity character rises, showing an increase from $58 \pm 4^{\circ}$ for a clean bare gold surface to $92-95^{\circ}$ for the modified surfaces. Similar trend was observed on carbon surfaces, with an increase of its hydrophobicity character from $58 \pm 2^{\circ}$ for the bare electrode to $72 \pm 2^{\circ}$ for the modified ones. Estimation of the thickness of the deposited organic layer can be performed by ellipsometry and AFM scratching experiments. Table 1 gathers all the results obtain on both gold and carbon modified surfaces.

Table 1. Ellipsometry, AFM scratching experiments and contact angle results obtained on gold and carbon substrates modified by cyclic voltammetry or fixed potential amperometry.

\begin{tabular}{|c|c|c|c|c|c|c|}
\hline & \multicolumn{3}{|c|}{ Gold } & \multicolumn{3}{c|}{ Carbon } \\
\hline $\begin{array}{c}\text { Modification } \\
\text { technique }\end{array}$ & $\begin{array}{c}\text { Thickness } \\
\text { (ellipsometry) }\end{array}$ & $\begin{array}{c}\text { Thickness } \\
\text { (AFM) }\end{array}$ & $\begin{array}{c}\text { Contact } \\
\text { angle }\end{array}$ & $\begin{array}{c}\text { Thickness } \\
\text { (ellipsometry) }\end{array}$ & $\begin{array}{c}\text { Thickness } \\
\text { (AFM) }\end{array}$ & $\begin{array}{c}\text { Contact } \\
\text { angle }\end{array}$ \\
\hline $\begin{array}{c}\text { Cyclic } \\
\text { voltammetry }\end{array}$ & $2.4 \pm 0.1 \mathrm{~nm}$ & $\begin{array}{c}2.4 \pm 1.0 \\
\mathrm{~nm}\end{array}$ & $95 \pm 5^{\circ}$ & $2.2 \pm 0.2 \mathrm{~nm}$ & $\begin{array}{c}1.7 \pm 0.4 \\
\mathrm{~nm}\end{array}$ & $78 \pm 2^{\circ}$ \\
\hline $\begin{array}{c}\text { Fixed potential } \\
\text { amperometry }\end{array}$ & $4.2 \pm 0.1 \mathrm{~nm}$ & $\begin{array}{c}4.3 \pm 1.1 \\
\mathrm{~nm}\end{array}$ & $92 \pm 3^{\circ}$ & $4.1 \pm 0.1 \mathrm{~nm}$ & $\begin{array}{c}3.6 \pm 0.5 \\
\mathrm{~nm}\end{array}$ & $78 \pm 1^{\circ}$ \\
\hline
\end{tabular}

As shown in Table 1, values of layer thickness obtained by ellipsometry were corroborated by AFM scratching experiments, both techniques showed a good agreement between them for modified gold electrodes as well as for carbon substrates. What follows next, the values got by ellipsometry will be used since its higher accuracy. Modification by fixed potential deposition leads to thicker organic films by comparison with cyclic voltammetry, from 4.2 and 4.1 to 2.4 and 2.2 for gold and carbon electrodes respectively. Regarding the electrochemical properties of 
the organic layer, a $2 \mathrm{~nm}$-film should allow the electron transfer by tunneling ${ }^{44,45}$ and, with this value of thickness, differentiate between direct electron transfer by pinholes or defects by only using outer-spbere redox probes may be difficult. Thus, the discussion will be focus on the electrochemical behavior of the thicker $4 \mathrm{~nm}$-aryldiazonium layer since, in this case, the tunneling electron transfer can be neglected. ${ }^{44}$ Experimental data performed on gold and carbon substrates by $\mathrm{CV}$ are shown in the supplementary information section. The molecular structure of tetraphenylmethane has been already reported in the literature. ${ }^{46}$ Based on the reported crystallographic structure, we derived a thickness of $1.1 \mathrm{~nm}$ for a monolayer of tetraphenylmethane. It is clear from these results that multilayered films are obtained both on gold and carbon substrates, with thicknesses equivalent to two monolayers for the thinnest films up to 3-4 monolayers for the thickest ones.

The chemical composition of the grafted organic layers was investigated by X-ray photoelectron spectroscopy (XPS) analyses. (Figure 2) XPS is preferentially performed with gold electrodes in order to mitigate the large carbon signal due to the substrate itself. Hence we will present here the results obtained on gold surfaces by fixed potential amperometry. The survey and high-resolution core level spectra show the presence of carbon C 1s (282-294 eV, $59.9 \%)$, gold $\mathrm{Au}$ 4f (84-88 eV, 38 \%), oxygen $\mathrm{O} 1 \mathrm{~s}(533 \mathrm{eV}, 0.9 \%)$ and nitrogen $\mathrm{N} \mathrm{1s} \mathrm{(398-404.5} \mathrm{eV,}$ $1.2 \%)$. The presence of intense $\mathrm{Au} 4 \mathrm{f}$ photoelectrons peaks is in agreement with the formation of thin organic layers onto the gold substrate (Figure S3). The N 1s core level spectrum could be decomposed into 2 components; a main component at $399.7 \mathrm{eV}$ attributed to $-\mathrm{N}=\mathrm{N}$ - azo linkage, ${ }^{47,48,49,50}$ and a small component corresponding to a $\pi-\pi^{*}$ shake-up satellite transition at $402.8 \mathrm{eV} .{ }^{49,50,51}$ There is no signal located at $\sim 404 \mathrm{eV}$, indicating that there is no remaining 
diazonium functions within the layer (Figure 2). The main contribution in the XPS analyses is due to carbon with a $\mathrm{C} 1 \mathrm{~s}$ peak that is fitted with three components centered at $285 \mathrm{eV}(\mathrm{C}-\mathrm{C} / \mathrm{C}$ H), $286.5 \mathrm{eV}$ (C-N, accounting for $\sim 10$ (at.) \% of the whole carbon signal) and $291.2 \mathrm{eV}\left(\pi-\pi^{*}\right)$ for the shake-up satellite transition. The presence of the $\mathrm{C} 1 \mathrm{~s}$ shake-up satellite definitively supports the attachment of aromatic aryl groups onto the surface. From these experiments, it could be concluded that the organic films are composed of carbon atoms in aryl groups and that there is a minimal amount of nitrogen atoms inside the layers. By considering the starting molecule, the atomic $\mathrm{N} / \mathrm{C}$ ratio is equal to $32 \%$ whereas this ratio decreases to $2 \%$ in the deposited organic films, corresponding to a very small amount of azo bridges present within the film. Similar qualitative observations and conclusions can be drawn on XPS experiments performed on carbon substrates functionalized by fixed potential amperometry. (Figure S4)

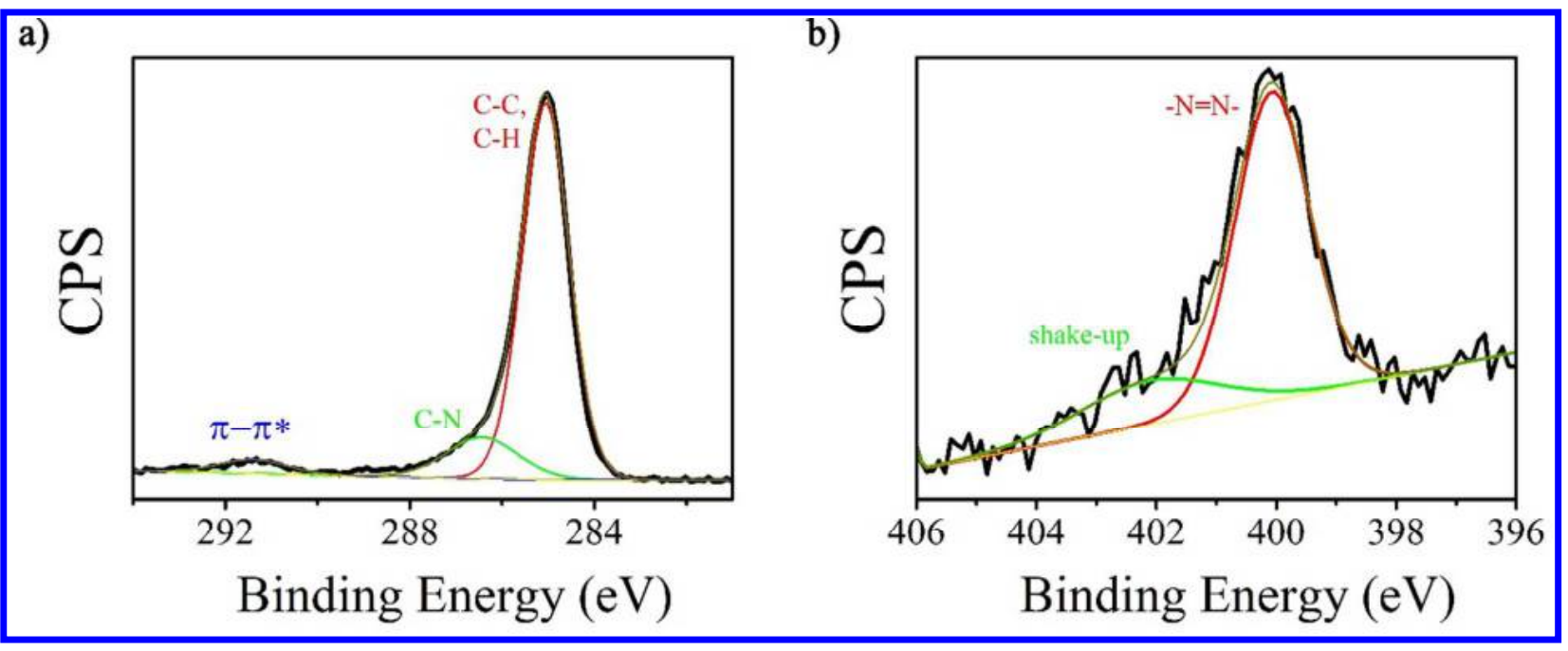

Figure 2. XPS peak-fitted C 1s (a) and N 1s (b) core level spectra for a gold surface modified by fixed potential amperometry. 
As a complementary characterization technique, Infrared absorption spectroscopy (IR) experiments were also performed on freshly prepared gold samples (Figure S5 and S6) confirming that diazonium functions do not remain inside the films. As discussed by Kanoufi et al ${ }^{52}$ or Locklin et $a l^{53}$, the post-functionalization of deposited organic films containing diazonium functions could be performed using the Gomberg-Bachmann reaction ${ }^{54}$ allowing aryl-aryl coupling. The reaction consists of dipping the modified surfaces in a solution containing an aromatic molecule immediately after grafting. We used ferrocene molecule in these experiments since it could easily be detected by an electrochemical method. No electrochemical signal of grafted ferrocene was evidenced after the post-functionalization experiments (Figure S7) confirming the absence of diazonium functions in the deposited organic films. In the work described by Locklin et al., ${ }^{53}$ the electro-reduction of $p$ benzene(bisdiazonium) ions leads to two irreversible reduction peaks. The authors ascribed these two reduction peaks to the reduction of each diazonium function. Stopping the reductive potential during electro-grafting at the first reduction peak leads to the immobilization of diazonium-functionalized (mono) layers, hence allowing post-functionalization by the Gomberg-Bachmann reaction. In our experiments, only one reduction peak was observed indicating that all diazonium functions are reduced at the same potential and explaining why there are no remaining active diazonium functions constituting the film. Furthermore, no electrochemical activity in reduction was detected when $\mathrm{CV}$ of modified substrates was performed in a pure electrolytic acetonitrile solution (Figure S8).

The blocking properties of the deposited organic thin films were examined by CV on a modified glassy carbon electrode in aqueous solution using dopamine and ferrocenemethanol 
$(\mathbf{F c M e O H})$ as redox probes. Dopamine has been chosen since its reversible oxidation to the corresponding $o$-quinone is highly sensitive to surface modification. ${ }^{55}$ Dopamine needs to reach the substrate to rapidly transfer its charge and thus it is especially suited for probing ultrathin organic films ${ }^{56,57}$, and for discriminating between direct and indirect charge transfer. ${ }^{58}$ As shown in Figure 3a, after electro-grafting of $\mathbf{C}\left(\mathbf{A r N}_{2}{ }^{+}\right)_{4}$ (blue curves), dopamine oxidation is totally inhibited. This shows that the deposited organic film is homogenous, without defects, and efficiently blocks the passage of dopamine from the solution to the substrate. However, FcMeOH oxidation remains observable (Figure 3b) but becomes totally irreversible, highlighting some unexpected electrochemical current rectification properties of the deposited organic film towards this redox probe in solution. The behavior difference between these two redox probes suggests that $\mathbf{F c M e O H}$ oxidation occurs via indirect charge transfer (tunneling). Considering that the layer thickness is estimated to be thicker than $4 \mathrm{~nm}$, this also indicates that the redox probe must penetrate inside the deposited organic thin film before charge transfer through tunneling. From these experiments, two specific properties of the ultrathin organic film were evaluated: (i) molecular sieving properties, where diffusion of the redox probe through the film is dependent on their size and (ii) current rectification properties.

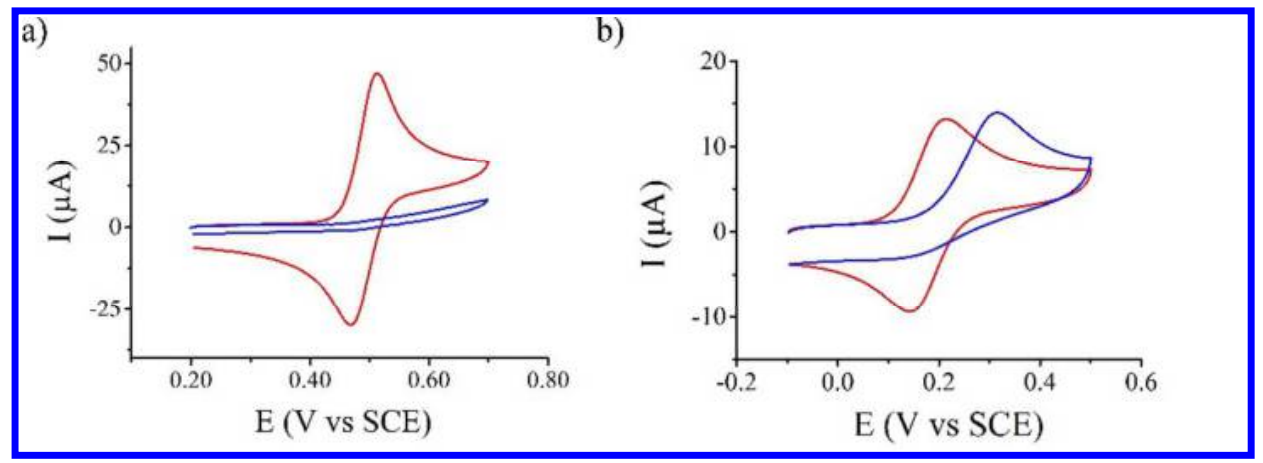


Figure 3. Cyclic voltammetry of a) $10^{-3} \mathrm{~mol} \mathrm{~L} \mathrm{~L}^{-1}$ dopamine aqueous solution $\left(+0.1 \mathrm{~mol} \mathrm{~L}^{-1}\right.$ $\left.\mathrm{H}_{2} \mathrm{SO}_{4}\right)$ and b) $10^{-3} \mathrm{~mol} \mathrm{~L}^{-1}$ ferrocenemethanol aqueous solution $\left(+0.1 \mathrm{~mol} \mathrm{~L}^{-1} \mathrm{KNO}_{3}\right)$ on a bare glassy carbon electrode (red curves) and on a carbon electrode modified by the electro-reduction of $\mathbf{C}\left(\mathrm{ArN}_{2}{ }^{+}\right)_{4}$ by fixed potential amperometry (blue curves). Scan rate: $100 \mathrm{mV} \mathrm{s}^{-1}$.

\section{Molecular sieving properties.}

Ferrocene (Fc), dimethylferrocene $\left(\mathbf{M e}_{2} \mathbf{F c}\right)$ and decamethylferrocene $\left(\mathbf{M e}_{10} \mathbf{F c}\right)$ were chosen as redox probes with increasing steric hindrance to probe the molecular sieving properties of the deposited organic thin film in acetonitrile. Their molecular volumes were estimated from DFT calculations. $^{40}$ (See experimental section) Their electrochemical behaviors are shown in Figure 4. As observed for FcMeOH in aqueous solution, totally irreversible oxidation is observed for Fc (Figure 4a) and $\mathbf{M e}_{2} \mathbf{F c}$ (Figure 4b), whereas $\mathbf{M e}_{\mathbf{1 0}} \mathbf{F c}$ (Figure 4c) oxidation is nearly totally suppressed. Moreover, while the oxidation peak current intensity of Fc at the modified electrode relatively to the one recorded at the bare surface is closed to unity $(0.89$, see Table 2 and Table $\mathrm{S} 1$ ), the $\mathrm{Me}_{2} \mathbf{F c}$ relative oxidation peak current intensity decrease to 0.81 . Increasing the steric hindrance of ferrocene derivatives leads to a monotonic decrease of their oxidation peak current intensities, until total inhibition of electron transfer. However from these sole experiments, such decrease of current could be explained by the variation of the potential applied to the modified working electrode as the substitution on the ferrocene probe changes the size but also its oxidation potential. Indeed, the polarization of the electrode could induce structural changes in the layer and consequently affects the passage of the redox probes through the film and the kinetics of the redox processes. ${ }^{59}$ In order to answer this question, two other ferrocene 
derivatives were considered: 1,1'-di(methylphenyl)ferrocene $\quad\left((\mathbf{P h M e})_{2} \mathbf{F c}\right)$ and 1(biphenylethynyl)ferrocene $\left(\mathbf{P h}_{\mathbf{2}} \mathbf{E F c}\right)$. Both derivatives have higher steric hindrance than $\mathbf{F c}$ but the half-wave potential $\left(\mathrm{E}_{1 / 2}\right)$ value of $(\mathbf{P h M e})_{2} \mathbf{F c}$ is $40 \mathrm{mV}$ lower than $\mathbf{F c}$ while the $\mathrm{E}_{1 / 2}$ value of $\mathbf{P h}_{2} \mathbf{E F c}$ is $130 \mathrm{mV}$ higher (see Table 2 and Figure 5, red curves). As shown in Figure 5, in both cases, the oxidations of the redox probes at the modified surfaces are totally irreversible with a relative peak current intensity lower than that obtained for $\mathbf{F c}$, being 0.73 and 0.79 respectively.
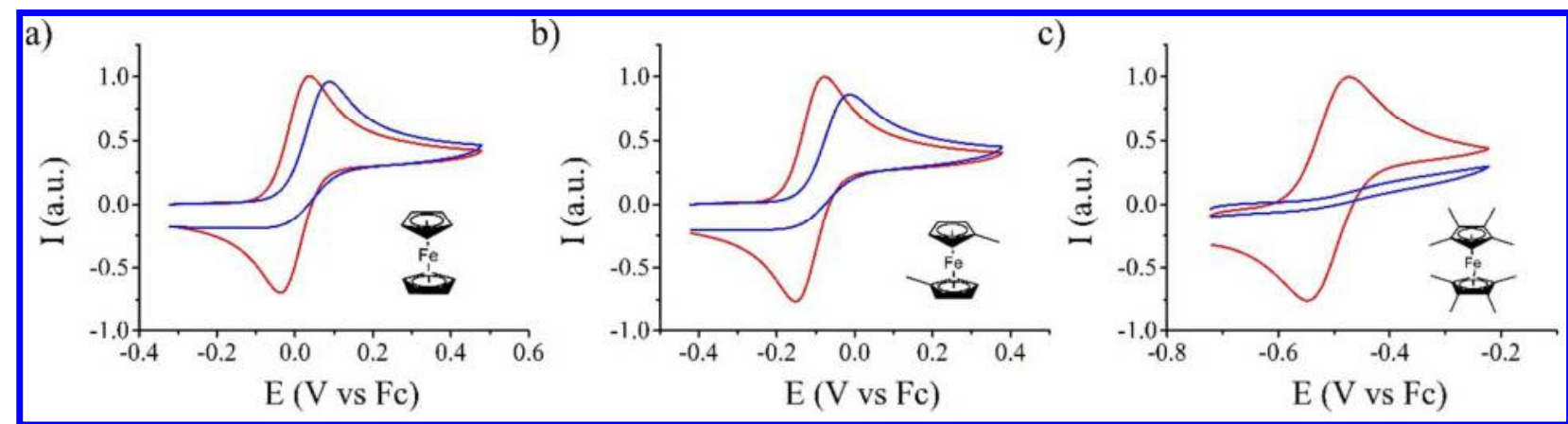

Figure 4. Cyclic voltammetry of a) $10^{-3} \mathrm{~mol} \mathrm{~L}^{-1}$ of ferrocene, b) $10^{-3} \mathrm{~mol} \mathrm{~L}^{-1}$ of dimethylferrocene and c) $10^{-3} \mathrm{~mol} \mathrm{~L}^{-1}$ of decamethylferrocene in acetonitrile solution $(+0.1 \mathrm{~mol}$ $\mathrm{L}^{-1} \mathrm{KPF}_{6}$ ) on bare glassy carbon electrodes (red curves) and on glassy carbon electrodes modified by fixed potential amperoamtry (blue curves). Scan rate: $100 \mathrm{mV} \mathrm{s}^{-1}$.

Similar experiments were performed on carbon substrates modified by CV (Table S2 and Figure S14) and on gold substrates modified by CV (Table S3 and Figure S15) and by fixed potential amperometry. (Table S4 and Figure S16) Gold and carbon substrates modified by CV showed slightly less blocking properties than those obtained by fixed potential amperometry as direct consequence of the differences previously observed in the layer thickness for electrodes modified by these two techniques. The main difference between gold and carbon surfaces 
concerns the reproducibility of the results; less reproducible data were obtained on modified gold substrates (SD 3-8\%) than on modified glassy carbon electrodes, in which an excellent reproducibility was achieved (SD 2-3\%). Despite of this, both gold and carbon modified surfaces showed similar trends: (i) a decrease in the oxidation peak current with increasing the size of the redox probe associated to (ii) an irreversible oxidation. All these results demonstrate that the decrease of the oxidation peak current intensities is correlated to the size of the redox probes and not to the potential applied. Thus, the electro-generated organic thin films present sieving properties.
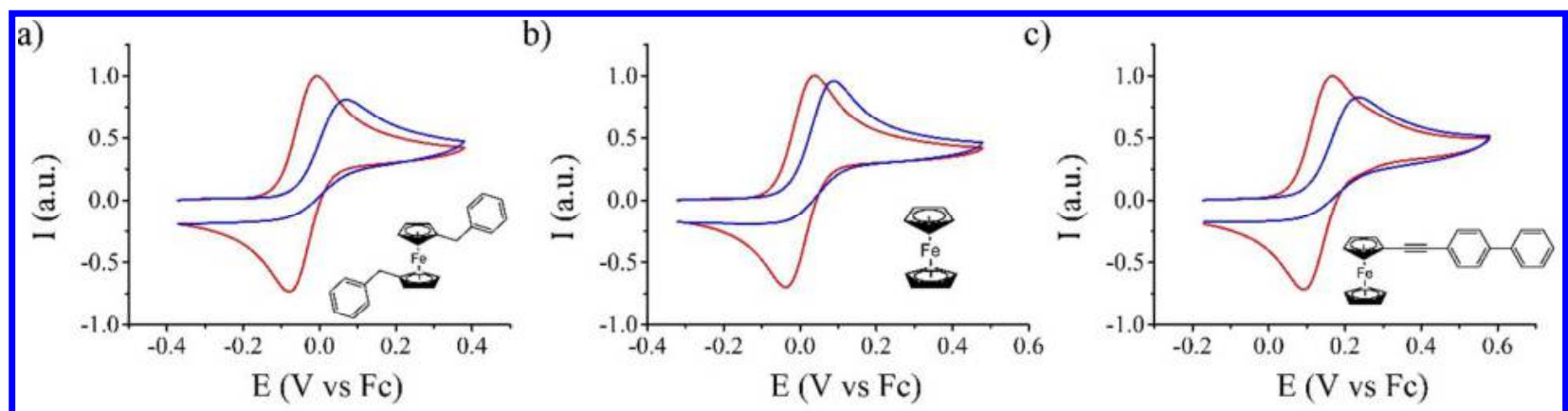

Figure 5. Cycle voltammetry of a) $10^{-3} \mathrm{~mol} \mathrm{~L}^{-1} 1,1^{\prime}$-di(methylphenyl)ferrocene, b) $10^{-3} \mathrm{~mol} \mathrm{~L}^{-1}$ of ferrocene and c) $10^{-3} \mathrm{~mol} \mathrm{~L}^{-1}$ of 1-(biphenylethynyl)ferrocene in a acetonitrile solution $(+0.1$ mol L $\mathrm{L}^{-1} \mathrm{KPF}_{6}$ ) on bare glassy carbon electrodes (red curves) and on glassy carbon electrodes modified by fixed potential amperometry (blue curves). Scan rate: $100 \mathrm{mV} \mathrm{s}^{-1}$.

Table 2. Half-wave potential $\mathrm{E}_{1 / 2}$, estimation of the relative oxidation peak intensity $(\Delta \mathrm{I})$ and steric hindrance of the different ferrocene derivatives.

\begin{tabular}{|c|c|c|c|c|c|}
\hline Redox probes & $\mathrm{Me}_{10} \mathrm{Fc}$ & $\mathrm{Me}_{2} \mathrm{Fc}$ & $\mathrm{Fc}$ & $(\mathrm{MePh})_{2} \mathrm{Fc}$ & $\mathrm{Ph}_{2} \mathrm{EFc}$ \\
\hline $\mathrm{E}_{1 / 2}\left(\mathrm{~V}\right.$ vs $\left.\mathrm{Fc} / \mathrm{Fc}^{+}\right)$ & -0.51 & -0.11 & 0 & -0.04 & 0.13 \\
\hline
\end{tabular}




\begin{tabular}{|c|c|c|c|c|c|}
\hline$\Delta \mathrm{I}$ & - & 0.81 & 0.89 & 0.73 & 0.79 \\
\hline Steric hindrance $\left(\AA^{3}\right)^{\mathrm{a}}$ & 740 & 397 & 382 & 796 & 724 \\
\hline
\end{tabular}

a Steric hindrance of each redox probe is calculated by DFT and defined as the molecular volume of each molecule. It has to be seen as a rough estimation since the geometry of the probes are different. Optimized geometries of each redox probe are displayed in the supplementary information section. (Figure S9-S13)

\section{Electrochemical current rectification properties.}

Most of electrochemical current rectifiers are based on mediated electron transfer. These are obtained with surfaces functionalized by redox entities, allowing a unidirectional current of redox probes in solution. In the present study, the rectification effect has a different origin since no redox entities are present within the deposited organic thin film as evidenced by the different characterization techniques (XPS, IR, CV). Additional experiments were performed to identify the origin of this phenomenon. We have tested a series of solution redox probe (Fc) with different concentrations up to $10^{-2} \mathrm{~mol} \mathrm{~L}^{-1}$. In this concentration range, the peak current intensity linearly depends on the concentration of Fc (Figure 6a), which confirms diffusion limitation of the redox probes. Additionally, increasing the scan rate doesn't increase the reversibility of the system for both thin and thick layers in the range of considered scan rates from 0.1 to $1 \mathrm{~V} \mathrm{~s}^{-1}$. (See supporting information section, Figure S17) Also the variation of the concentration of the redox probe was studied; the reversibility of the system is independent of the redox probe concentration. Figure $6 \mathrm{~b}$ represents the current peak intensities of a $10^{-3} \mathrm{~mol} \mathrm{~L}^{-1}$ Fc acetonitrile solution at different scan rates at bare and modified GC surface. As expected for a diffusionlimiting regime, a linear dependency of the current peak intensity $\left(\mathrm{I}_{\text {peak }}\right)$ as a function of the square root of the scan rate $\left(\mathrm{v}^{1 / 2}\right)$ is observed. However, a clear diminution of the diffusion coefficient of Fc is observed when the modified electrode is used as working electrode. Thus, the 
apparent diffusion coefficient of Fc is found to be nearly 5 times lower $\left(5.710^{-6} \mathrm{~cm}^{2} \mathrm{~s}^{-1}\right)$ in the organic layer than in acetonitrile solution $\left(2.710^{-5} \mathrm{~cm}^{2} \mathrm{~s}^{-1}\right)$. (See supporting information section) The low apparent diffusion coefficient of Fc inside the organic layer suggests that the pore of the organic layer are close to the size of the redox probe.
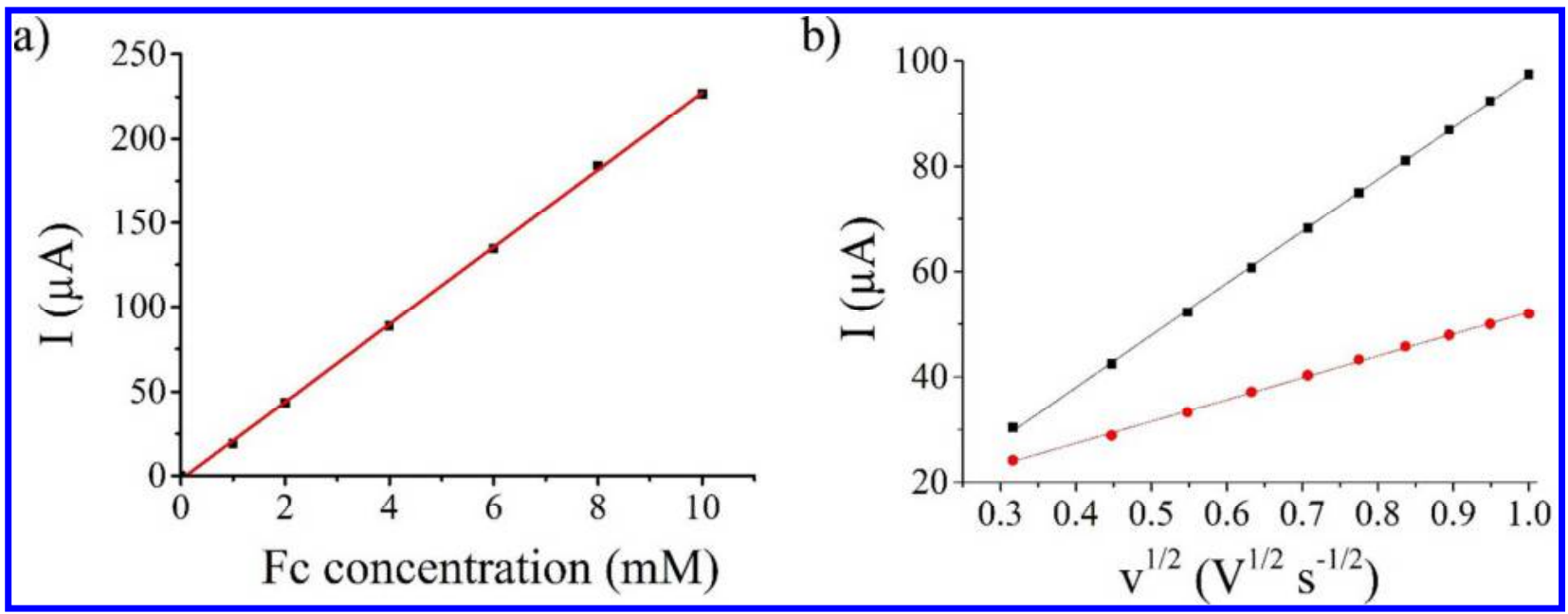

Figure 6. a) Variation of the anodic peak current with the concentration of ferrocene (Fc) redox probe in solution at a glassy carbon (GC) electrode modified by the electro-reduction of $\mathbf{C}\left(\mathrm{ArN}_{2}{ }^{+}\right)_{4}$ at $100 \mathrm{mV} \mathrm{s}^{-1}$. b) Variation of the anodic peak current with the square root of the scan rates of a $10^{-3} \mathrm{~mol} \mathrm{~L}^{-1} \mathbf{F c}$ acetonitrile solution at a bare GC electrode (red squares) and at a GC electrode modified by the electro-reduction of $\mathbf{C}\left(\mathbf{A r N}_{2}{ }^{+}\right)_{4}$ (black squares). Lines are linear fitting curves.

As evidenced before, the redox probe needs to diffuse inside the pores of the organic layer prior to the charge transfer. A change of the charge of the redox probe is accompanied by variations of the electrolyte composition present inside the film as reported for charge/discharge processes of conducting polymers where it is possible to control the electrochemical response by 
changing the size of the anion in polyaniline. ${ }^{60}$ By analogy with our case, this should create movements of cations and anions entering or leaving the film by the same pore channels than those used by the probe. It is thus interesting to evaluate how the size of the supporting salts constituting the electrolyte could affect the electrochemical response of the probe. In that purpose, a series of supporting salts presenting different size of cation or anion was considered. (Figure 7)

In a first series of experiments, the nature of the electrolyte cation was considered when the anion remaining the same. Potassium hexafluorophosphate $\left(\mathrm{KPF}_{6}\right.$, Figure 7a), tetraethylammonium hexafluorophosphate $\left(\mathrm{Et}_{4} \mathrm{NPF}_{6}\right.$, Figure $\left.7 \mathrm{~b}\right)$ and tetraoctylammonium hexafluorophosphate $\left(n \mathrm{Oc}_{4} \mathrm{NPF}_{6}\right.$, Figure $\left.7 \mathrm{c}\right)$ were chosen as supporting salts containing monovalent cations having different size. As previously observed, a decrease of the current peak intensity and irreversibility of the electrochemical signal are observed for Fc oxidation in all the electrolytes. Even if the cation size does not seem to have an effect on the irreversibility of the system, the bulkiest the cation is, the larger is the decrease of the peak current intensity. As shown in Table 3, this behavior is reproducible on all modified surfaces, on gold and carbon substrates modified by thin $(\sim 2 \mathrm{~nm})$ and thick $(\sim 4 \mathrm{~nm})$ organic films. If we consider that ferrocene is oxidized once it is inside the film, its oxidation should be accompanied by repulsion of cations that were "trap" inside the film to maintain charge balance. Considering that the pore size of the deposited organic films is fixed, the bigger the cation is, the more difficult is the ejection of this cation from the organic film to the solution, resulting in smaller oxidation current. This phenomenon thus supports the sieving properties of the organic films. 

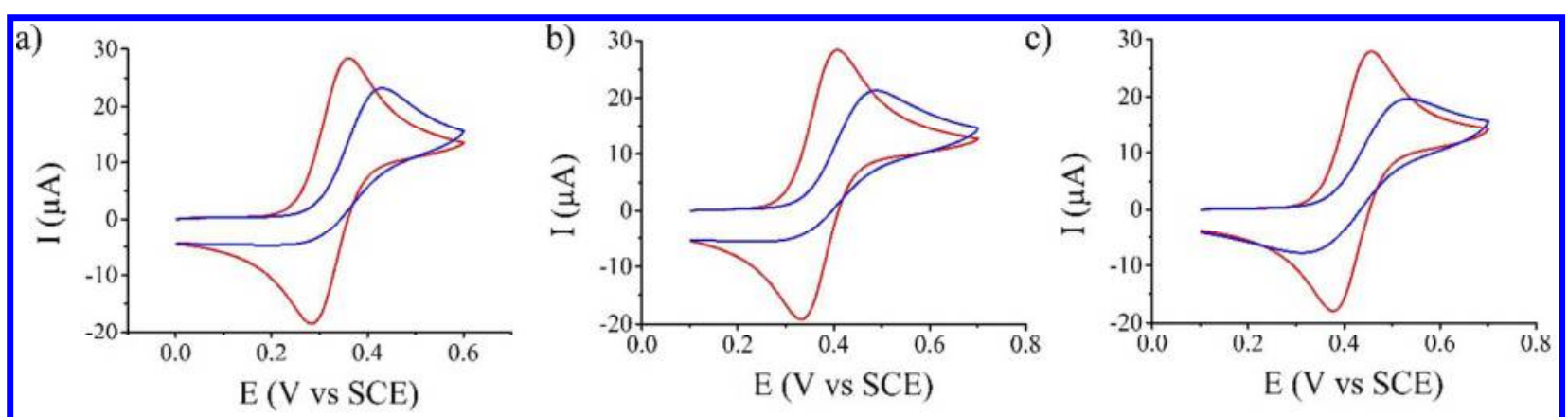

d)

e)

f)
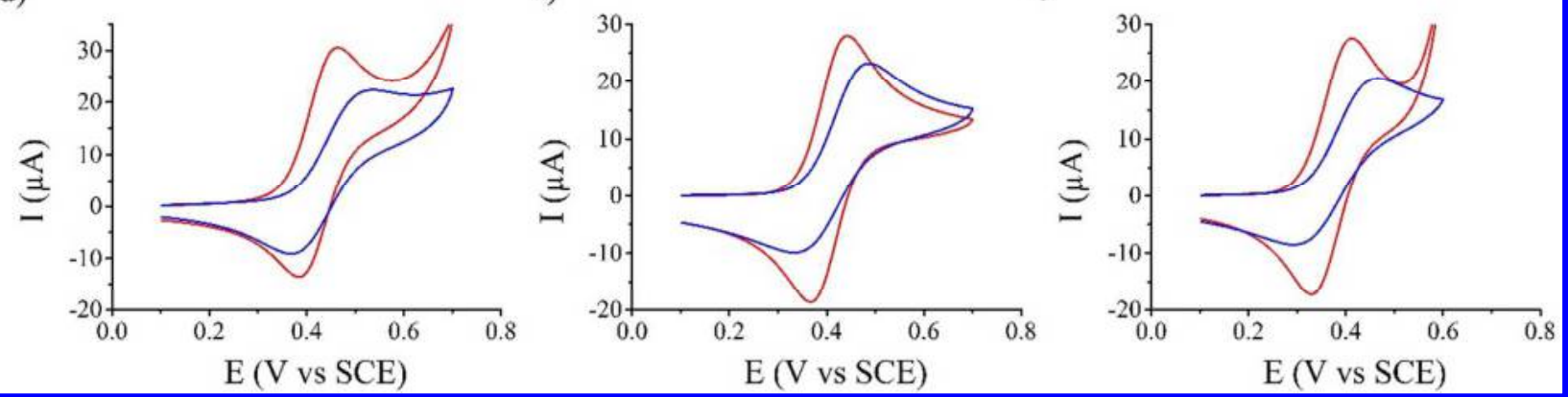

Figure 7. Cyclic voltammetry of $10^{-3} \mathrm{~mol} \mathrm{~L}^{-1}$ of ferrocene in acetonitrile solution containing a) $0.1 \mathrm{~mol} \mathrm{~L}^{-1}$ potassium hexafluorophosphate $\left(\mathrm{KPF}_{6}\right)$, b) $0.1 \mathrm{~mol} \mathrm{\textrm {L } ^ { - 1 }}$ tetraethylammonium hexafluorophosphate $\left(\mathrm{Et}_{4} \mathrm{NPF}_{6}\right)$, c) $0.1 \mathrm{~mol} \mathrm{~L}^{-1}$ tetraoctylammonium hexafluorophosphate $\left(n \mathrm{Oc}_{4} \mathrm{NPF}_{6}\right)$, d) $0.1 \mathrm{~mol} \mathrm{\textrm {L } ^ { - 1 }}$ tetrabutylammonium chloride $\left(n \mathrm{Bu}_{4} \mathrm{NCl}\right)$, e) $0.1 \mathrm{~mol} \mathrm{\textrm {L } ^ { - 1 }}$ tetrabutylammonium tetrafluoroborate $\left(n \mathrm{Bu}_{4} \mathrm{NBF}_{4}\right)$ and f) $0.1 \mathrm{~mol} \mathrm{~L} \mathrm{~L}^{-1}$ tetrabutylammonium tetraphenylborate $\left(n \mathrm{Bu}_{4} \mathrm{NBPh}_{4}\right)$, on bare carbon electrodes (red curves) and on carbon electrodes modified by thick organic films (blues curves). Scan rate: $100 \mathrm{mV} \mathrm{s}^{-1}$.

Table 3. Estimation of the relative oxidation peak intensity $\left(\Delta \mathrm{I}_{\mathrm{ox}}\right)$ of a $10^{-3} \mathrm{~mol} \mathrm{~L}^{-1}$ ferrocene acetonitrile solution on carbon and gold substrate modified by thin and thick organic films with different supporting electrolytes.

\begin{tabular}{|l|c|c|c|c|}
\hline$\Delta \mathrm{I}_{\mathrm{ox}}$ & $\mathrm{GC}$ thin layer & GC thick layer & Au thin layer & Au thick layer \\
\hline $\mathrm{KPF}_{6}$ & $91 \pm 2 \%$ & $89 \pm 3 \%$ & $97 \pm 4 \%$ & $96 \pm 3 \%$ \\
\hline
\end{tabular}




\begin{tabular}{|l|c|c|c|c|}
\hline$n \mathrm{Et}_{4} \mathrm{NPF}_{6}$ & $65 \pm 3 \%$ & $81 \pm 8 \%$ & $84 \pm 2 \%$ & $79 \pm 4 \%$ \\
\hline$n \mathrm{Oc}_{4} \mathrm{NPF}_{6}$ & $61 \pm 4 \%$ & $76 \pm 8 \%$ & $85 \pm 1 \%$ & $80 \pm 10 \%$ \\
\hline
\end{tabular}

In a second series of experiments, the nature of the anion was evaluated keeping the same cation. Tetrabutylammonium chloride $\left(n \mathrm{Bu}_{4} \mathrm{NCl}\right.$, Figure $\left.7 \mathrm{~d}\right)$, tetrabutylammonium tetrafluoroborate $\left(n \mathrm{Bu}_{4} \mathrm{NBF}_{4}\right.$, Figure $\left.7 \mathrm{e}\right)$ and tetrabutylammonium tetraphenylborate $\left(n \mathrm{Bu}_{4} \mathrm{NBPh}_{4}\right.$, Figure $\left.7 \mathrm{f}\right)$ were chosen as supporting salts containing monovalent anions with different sizes. For all electrolytes, we observed for Fc oxidation at the modified electrode (blue curves) a decrease of the peak current intensity and the irreversibility of the electrochemical signal, compared to bare GC (red curves). However, the irreversibility of the electrochemical signal, leading to electrochemical current rectification, is more pronounced for the bulkiest anion. Table 4 shows the results obtained on both gold and carbon surfaces functionalized by thin and thick organic films. It was not possible to use $n \mathrm{Bu} 4 \mathrm{NCl}$ as supporting electrolyte for experiments performed with gold substrates as the chloride anions are oxidized before ferrocene redox probe. However, on all modified surfaces the same trend is observed, except for gold surfaces modified by CV where it is difficult to conclude.

Table 4. Estimation of the relative reduction peak intensity $\left(\Delta \mathrm{I}_{\text {red }}\right)$ of a $10^{-3} \mathrm{~mol} \mathrm{~L}^{-1}$ ferrocene acetonitrile solution on carbon and gold substrate modified by thin and thick organic films with different supporting electrolytes.

\begin{tabular}{|l|c|c|c|c|}
\hline $\mathrm{Fc} / \Delta \mathrm{I}_{\text {red }}$ & GC thin layer & GC thick layer & Au thin layer & Au thick layer \\
\hline$n \mathrm{Bu}_{4} \mathrm{NCl}$ & $58 \pm 2 \%$ & $70 \pm 5 \%$ & - & - \\
\hline
\end{tabular}




\begin{tabular}{|l|c|c|c|c|}
\hline$n \mathrm{Bu}_{4} \mathrm{NBF}_{4}$ & $53 \pm 10 \%$ & $57 \pm 6 \%$ & $72 \pm 4 \%$ & $62 \pm 11 \%$ \\
\hline$n \mathrm{Bu}_{4} \mathrm{NBPh}_{4}$ & $31 \pm 8 \%$ & $54 \pm 6 \%$ & $73 \pm 8 \%$ & $58 \pm 12 \%$ \\
\hline
\end{tabular}

This series of experiments shows that the reversibility of the system depends on the nature of the counter-ions transport inside the same pores. It explains why the size of the ions constituting the electrolyte along with its charge to balance have a strong impact on the current rectification properties and peak current intensities. The limitation in movement of the ions entering and leaving the film is responsible of the observed rectification effect. It is clear that the structure of the deposited organic layer is responsible of this specific property and that molecular sieving properties and current rectification properties are closely linked.

\section{Conclusions}

The electro-reduction of a tetrahedral-shape pre-organized tetra-aryldiazonium salts, tetrakis(4phenyldiazonium tetrafluoroborate)methane $\mathbf{C}\left(\mathbf{A r N}_{2}{ }^{+}\right)_{4}$, leads to the deposition of ultrathin organic films on gold and carbon substrates. Various characterization techniques as XPS, IR and $\mathrm{CV}$ shows that all diazonium functions have been reduced in the organic layer, which appears to be essentially composed of carbon and hydrogen atoms. Molecular sieving properties were evidenced by cyclic voltammetry of solution-phase redox probe in aqueous and organic solution. Substrates modified by this technique behave also as electrochemical current rectifiers (ECR). Due to the lack of redox relay in the layer, it appears to be different from the classical ECR as described by Murray et al. The transport of the redox molecules and of the counter-ions in the 
layer has been evidenced as responsible of the electrochemical current rectification properties of the modified materials. Both molecular sieving and electrochemical current rectification properties are related to the specific organization of the grafted ultrathin organic layer. Observation of both molecular sieving and electrochemical current rectification properties has never been observed previously for organic films electro-generated by the reduction of aryldiazonium ions that do not present this tetrahedral pre-organization. ${ }^{61,62,63,64}$

\title{
ASSOCIATED CONTENT
}

Supporting Information. XPS survey, Infra-red absorption spectroscopy, post-functionalization experiments and electro-activity of the modified electrode. The following files are available free of charge.

\section{Corresponding Author}

* Email: yann.leroux@univ-rennes1.fr

\section{Author Contributions}

The manuscript was written through contributions of all authors. All authors have given approval to the final version of the manuscript. All authors contributed equally.

\author{
ACKNOWLEDGMENT \\ J. Hamon (Institut des Matériaux de Nantes, Nantes, France) is thanked for his help in recording \\ the XPS spectra. Y.A. thanks the French Ministry of Research for financial support.
}

\section{REFERENCES}


(1) Delamar, M.; Hitmi, R.; Pinson, J.; Saveant, J.-M. Covalent modification of carbon surfaces by grafting of functionalized aryl radicals produced from electrochemical reduction of diazonium salts. J.Am.Chem.Soc. 1992, 114, 5883-5884.

(2) Nielsen, L. T.; Vase, K. H.; Dong, M.; Besenbacher, F.; Pedersen, S. U.; Daasbjerg, K. Electrochemical Approach for Constructing a Monolayer of Thiophenolates from Grafted Multilayers of Diaryl Disulfides. J.Am.Chem.Soc. 2007, 129, 1888-1889.

(3) Combellas, C.; Kanoufi, F.; Pinson, J.; Podvorica, F. I. Sterically Hindered Diazonium Salts for the Grafting of a Monolayer on Metals. J.Am.Chem.Soc. 2008, 130 (27), 8576-8577.

(4) Lee, L.; Ma, H.; Brooksby, P. A.; Brown, S. A.; Leroux, Y. R.; Hapiot, P.; Downard, A. J. Covalently anchored carboxyphenyl monolayer via aryldiazonium ion grafting: a well-defined reactive tether layer for on-surface chemistry. Langmuir $\mathbf{2 0 1 4}, 30$ (24), 7104-7111.

(5) Fontaine, O.; Ghilane, J.; Martin, P.; Lacroix, J.-C.; Randriamahazaka, H. Ionic Liquid Viscosity Effects on the Functionalization of Electrode Material through the Electroreduction of Diazonium. Langmuir 2010, 26 (23), 18542-18549.

(6) Mattiuzzi, A.; Jabin, I.; Mangeney, C.; Roux, C.; Reinaud, O.; Santos, L.; Bergamini, J.-F.; Hapiot, P.; Lagrost, C. Electrografting of Calix[4]arenediazonium Salts to Form Versatile Robust Platforms for Spatially Controlled Surface Functionalization. Nat.Commun. 2012, 3, 1130.

(7) Cao, L.; Fang, G.; Wang, Y. Electroreduction of Viologen Phenyl Diazonium Salts as a Strategy To Control Viologen Coverage on Electrodes. Langmuir 2017, 33, 980-987. 
(8) Bousquet, A.; Ceccato, M.; Hinge, M.; Pedersen, S. U.; Daasbjerg, K. Redox Grafting of Diazotated Anthraquinone as a Means of Forming Thick Conducting Organic Films. Langmuir 2012, 28, 1267-1275.

(9) Adenier, A.; Combellas, C.; Kanoufi, F.; Pinson, J.; Podvorica, F. I. Formation of Polyphenylene Films on Metal Electrodes by Electrochemical Reduction of Benzenediazonium Salts. Chem. Mater. 2006, 18, 2021-2029.

(10) Hicks, J. M.; Wong, Z. Y.; Scurr, D. J.; Silman, N.; Jackson, S. K.; Mendes, P. M.; Aylott, J. W.; Rawson, F. J. Tailoring the Electrochemical Properties of Carbon Nanotube Modified Indium Tin Oxide via in Situ Grafting of Aryl Diazonium. Lanomuir 2017, 33, 4924-4933.

(11) Pinson, J.; Podvorica, F. Attachment of organic layers to conductive or semiconductive surfaces by reduction of diazonium salts. Chem. Soc. Rev. 2005, 34, 429-439.

(12) Gohier, A.; Nekelson, F.; Helezen, M.; Jegou, P.; Deniau, G.; Palacin, S.; MayneL'Hermite, M. Tunable grafting of functional polymers onto carbon nanotubes using diazonium chemistry in aqueous media. J.Mater. Chem. 2011, 21, 4615-4622.

(13) Troian-Gautier, L.; Martinez-Tong, D. E.; Hubert, J.; Reniers, F.; Sferrazza, M.; Mattiuzzi, A.; Lagrost, C.; Jabin, I. Controlled modification of polymer surfaces through grafting of Calix[4]-tetradiazoate salts. J.Phvs.Chem.C 2016, 120, 22936-22945.

(14) Mesnage, A.; Lefèvre, X.; Jégou, P.; Deniau, G.; Palacin, S. Spontaneous Grafting of Diazonium Salts: Chemical Mechanism on Metallic Surfaces. Langmuir 2012, 28, 11767-11778. 
(15) Combellas, C.; Delamar, M.; Kanoufi, F.; Pinson, J.; Podvorica, F. I. Spontaneous Grafting of Iron Surfaces by Reduction of Aryldiazonium Salts in Acidic or Neutral Aqueous Solution. Application to the Protection of Iron against Corrosion. Chem. Mater. 2005, 17, 39683975.

(16) Schaming, D.; Nguyen, V.-Q.; Martin, P.; Lacroix, J.-C. Tunable Plasmon Resonance of Gold Nanoparticles Functionalized by Electroactive Bisthienylbenzene Oligomers or Polythiophene. L.Phys. Chem.C 2014, 118, 25158-25166.

(17) Menanteau, T.; Benoit, C.; Breton, T.; Cougnon, C. Enhancing the performance of a diazonium-modified carbon supercapacitor by controlling the grafting process. Electrochem. Comm. 2016, 63, 70-73.

(18) Yan, H.; Bergen, A; J.; McCreery, R. L. All-Carbon Molecular Tunnel Junctions. J.Am. Chem.Soc. 2011, 133, 19168-19177.

(19) Sayed, S. Y.; Bayat, A.; Kondratenko, M.; Leroux, Y.; Hapiot, P.; McCreery, R. L. Bilayer Molecular Electronics: All-Carbon Electronic Junctions Containing Molecular Bilayers Made with "Click” Chemistry. J.Am.Chem.Soc. 2013, 135, 12972-12975.

(20) Abruna, H. D.; Denisevich, P.; Umana, M.; Meyer, T. J.; Murray, R. W; Rectifying interfaces using two-layer films of electrochemically polymerized vinylpyridine and vinylbipyridine complexes of ruthenium and iron on electrodes. J.Am. Chem. Soc. 1981, 103, 15. 
(21) Alleman, K. S.; Weber, K.; Creager, S. E. Electrochemical Rectification at a MonolayerModified Electrode. L.Phys. Chem. 1996, 100, 17050-17058.

(22) Motiei, L.; Kaminker, R.; Sassi, M.; van der Boom, M. E. Molecule and Electron Transfer through Coordination-Based Molecular Assemblies. J. Am. Chem. Soc. 2011, 133, 14264-14266.

(23) Liu, Y.; Offenhäusser, A.; Mayer, D. Electrochemical current rectification at biofunctionalized electrodes. Bioelectrochemistrv 2010, 77, 89-93.

(24) Oh, S.-K.; Baker, L. A.; Crooks, R. M. Electrochemical Rectification Using Mixed Monolayers of Redox-Active Ferrocenyl Dendrimers and n-Alkanethiols. Langmuir 2002, 18, 6981-6987.

(25) Liu, Y.; Wang, E.; Dong, S. Rectification behaviors based on redox-active molecular systems. Electrochem. Comm. 2011, 13, 906-908.

(26) Fave, C.; Leroux, Y.; Trippe, G.; Randriamahazaka, H.; Noel, V.; Lacroix, J.-C. Tunable Electrochemical Switches Based on Ultrathin Organic Films. J.Am.Chem.Soc. 2007, 129, 1890-1891.

(27) Zhu, Y.; Gupta, K. M.; Liu, Q.; Jiang, J.; Caro, J.; Huang, A. Synthesis and seawater desalination of molecular sieving zeolitic imidazolate framework membranes. Desalination 2016, 385, 75-82.

(28) Ghoufi, A.; Benhamed, K.; Boukli-Hacene, L.; Maurin, G. Electrically Induced Breathing of the MIL-53(Cr) Metal-Organic Framework. ACS Cent. Sci. 2017, in press, DOI: 10.1021/acscentsci.6b00392. 
(29) Duke, M. C.; Diniz da Costa, J. C.; Lu, G. Q.; Petch, M.; Gray, P. Carbonised template molecular sieve silica membranes in fuel processing systems: permeation, hydrostability and regeneration. L.Membr.Sci. 2004, 241, 325-333.

(30) Vilà, N.; André, E.; Ciganda, R. ; Ruiz, J.; Astruc, D.; Walcarius, A. Molecular Sieving with Vertically Aligned Mesoporous Silica Films and Electronic Wiring through Isolating Nanochannels. Chem. Mater. 2016, 28, 2511-2514.

(31) Kandambeth, S.; Biswal, B. P.; Chaudhari, H. D.; Rout, K. C.; Kunjattu, S. H.; Mitra, S.; Karak, S.; Das, A.; Mukherjee, R.; Kharul, U. K.; Banerjee, R. Selective Molecular Sieving in Self-Standing Porous Covalent-Organic-Framework Membranes. Adv_.Mater. 2017, 29, 1603945.

(32) Bélanger, S.; Stevenson, K. J.; Mudakha, S. A.; Hupp, J. T. "Perfect” Electrochemical Molecular Sieving by Thin and Ultrathin Metallopolymeric Films. Langmuir 1999, 15, 837-843.

(33) Koenig, S. P.; Wang, L.; Pellegrino, J.; Bunch, J. S. Selective molecular sieving through porous graphene.

(34) Seo, D.-J.; Gou, Z.; Fujita, H.; Fujii, T.; Sakoda, A. Simple fabrication of molecular sieving carbon for biogas upgrading via a temperature controlled carbonization of Phyllostachys pubescens. Renew. Energy 2016, 86, 693-702. Nat. Nanotech. 2012, 7, 728-732.

(35) Li, Z.; Dai, S.; Surface Functionalization and Pore Size Manipulation for Carbons of Ordered Structure. Chem.Mater. 2005, 17, 1717-1721. 
(36) Wang, X.; Liu , R.; Waje, M. M.; Chen, Z.; Yan, Y.; Bozhilov, K. N.; Feng, P. Sulfonated Ordered Mesoporous Carbon as a Stable and Highly Active Protonic Acid Catalyst. Chem.Mater. 2007, 19, 2395-2397.

(37) Brooksby, P. A.; Downard, A. J. Electrochemical and Atomic Force Microscopy Study of Carbon Surface Modification via Diazonium Reduction in Aqueous and Acetonitrile Solutions. Langmuir 2004, 20, 5038-5045.

(38) Anariba, F.; DuVall, S. H.; McCreery, R. L. Mono- and Multilayer Formation by Diazonium Reduction on Carbon Surfaces Monitored with Atomic Force Microscopy “Scratching". Anal.Chem. 2003, 75, 3837-3844.

(39) http://gwyddion.net/.

(40) Gaussian 09, Revision B.01, Frisch, M. J.; Trucks, G. W.; Schlegel, H. B.; Scuseria, G. E.; Robb, M. A.; Cheeseman, J. R.; Scalmani, G.; Barone, V.; Mennucci, B.; Petersson, G. A.; Nakatsuji, H.; Caricato, M.; Li, X.; Hratchian, H. P.; Izmaylov, A. F.; Bloino, J.; Zheng, G.; Sonnenberg, J. L.; Hada, M.; Ehara, M.; Toyota, K.; Fukuda, R.; Hasegawa, J.; Ishida, M.; Nakajima, T.; Honda, Y.; Kitao, O.; Nakai, H.; Vreven, T.; Montgomery, J. A., Jr.; Peralta, J. E.; Ogliaro, F.; Bearpark, M.; Heyd, J. J.; Brothers, E.; Kudin, K. N.; Staroverov, V. N.; Kobayashi, R.; Normand, J.; Raghavachari, K.; Rendell, A.; Burant, J. C.; Iyengar, S. S.; Tomasi, J.; Cossi, M.; Rega, N.; Millam, J. M.; Klene, M.; Knox, J. E.; Cross, J. B.; Bakken, V.; Adamo, C.; Jaramillo, J.; Gomperts, R.; Stratmann, R. E.; Yazyev, O.; Austin, A. J.; Cammi, R.; Pomelli, C.; Ochterski, J. W.; Martin, R. L.; Morokuma, K.; Zakrzewski, V. G.; Voth, G. A.; Salvador, P.; 
Dannenberg, J. J.; Dapprich, S.; Daniels, A. D.; Farkas, O.; Foresman, J. B.; Ortiz, J. V.; Cioslowski, J.; Fox, D. J. Gaussian, Inc.: Wallingford, CT, 2010.

(41) Gaussian 09 User's Reference. Manual Version 8.0, 2009, Page 272.

(42) Saby, C.; Ortiz, B.; Champagne, G. Y.; Bélanger, D. Electrochemical Modification of Glassy Carbon Electrode Using Aromatic Diazonium Salts. 1. Blocking Effect of 4-Nitrophenyl and 4-Carboxyphenyl Groups. Langmuir 1997, 13, 6805-6813.

(43) Benedetto, A.; Balog, M.; Viel, P.; Le Derf, F.; Salle, M.; Palacin, S. Electro-Reduction of Diazonium Salts on Gold: Why Do We Observe Multi-Peaks? Electrochim. Acta 2008, 53, 71177122.

(44) Shein, J. B.; Lai, L. M. H.; Eggers, P. K.; Paddon-Row, M. N.; Gooding, J. J. Formation of Efficient Electron Transfer Pathways by Adsorbing Gold Nanoparticles to Self-Assembled Monolayer Modified Electrodes. Langmuir 2009, 25, 11121-11128.

(45) Lhenry, S.; Jalkh, J.; Leroux, Y. R.; Ruiz, J.; Ciganda, R.; Astruc, D.; Hapiot, P. Tunneling Dendrimers. Enhancing charge transport through insulating layer using redox molecular objects. L.Am.Chem.Soc. 2014, 136, 17950-17953.

(46) Claborn, K.; Kahr, B.; Kaminsky, W. Calculations of optical properties of the tetraphenyl$\mathrm{X}$ family of isomorphous crystals (X C , Si, Ge, Sn, Pb). CrustEngComm 2002, 4, 252-256.

(47) Gam-Derouich, S.; Carbonnier, B.; Turmine, M.; Lang, P.; Jouini, M.; Ben HassenChehimi, D.; Chehimi, M. M., Electrograted Aryl Diazonium initiators for Surface-Confined 
Photopolymerization : A New Approach to designing Functional Polyler Coatings. Langmuir, 2010, 26, 11830-11840.

(48) Schmidt, R.; McNellis, E.; Freyer, W.; Brete, D.; Giessel, T.; Gahl, C.; Rueter, K.; Weinelt, M. Azobenzene-functionalized alkanothiols in self-assembeld monolayers on gold. Appl. Phvs. A 2008, 93, 267-275.

(49) Ulrich, S.; Jung, U.; Strunkus, T.; Schütt, C.; Bloedorn, A.; Lemnke, S.; Ludwig, E.; Kipp, L; Faupel, F.; Maqgnusse, O.; Herges, R. X-ray spectroscopy characterization of azobenzenefunctionalized triazatriangulenium adlayers on Au (111) surfaces. PCCP 2015, 17, 17053-17062.

(50) Gahl, C.; Schmidt, R.; Brete, D.; Paarmann, S.; Weinelt, M. Chare-transfer Dynamics in Azobenzene Alkanethiolate Self-Assembled Monolayers on Gold. Surf. Sci. 2016, 643, 183-189.

(51) Nakayama, Y.; Takahagi, T.; Soeda, F.; Ishitani, A.; Shimomura, M.; Kunitake, T. XPS Study of Oriented Organic Molecules. L.Colloids and Intef.Sci. 1988, 122, 464-474.

(52) Hazimeh, H.; Piogé, S.; Pantoustier, N.; Combellas, C.; Podvorica, F. I.; Kanoufi, F. Radical Chemistry from Diazonium-Terminated Surfaces. Chem. Mater. 2013, 25, 605-612.

(53) Marshall, N.; Locklin, J. Reductive Electrografting of Benzene ( $p$-Bisdiazonium Hexafluorophosphate): A Simple and Effective protocol for Creating Diazonium-Functionalized Thin Films. Langmuir 2011, 27, 13367-13373.

(54) Gomberg, M.; Bachmann, W. E. The Synthesis of Biaryl Compounds by Means of the Diazo Reaction. LAm.Chem.Soc. 1924, 46, 2339-2343. 
(55) DuVall, S. H.; McCreery, R. L. Control of Catechol and Hydroquinone Electron-Transfer Kinetics on Native and Modified Glassy Carbon Electrodes. Anal. Chem. 1999, 71, 4594-4602.

(56) Santos, L.; Mattiuzzi, A.; Jabin, I.; Vandencasteele, N.; Reniers, F.; Reinaud, O.; Hapiot, P.; Lhenry, S.; Leroux, Y.; Lagrost, C. J.Phvs. Chem.C 2014, 118, 15919-15928.

(57) Jalkh, J.; Thiery, S.; Bergamini, J.-F.; Hapiot, P.; Poriel, C.; Leroux, Y. R. J.Phvs. Chem. C 2017, 121, 14228-14237.

(58) Lhenry, S.; Leroux, Y. R.; Hapiot, P. Use of Catechol as Selective Redox Mediator in Scanning Electrochemical Microscopy Investigations. Anal. Chem. 2012, 84, 7518-7524.

(59) Traulsen, M. L.; de Carvalho, H. W. P.; Zielke, P.; Grunwaldt, J. -D. The Effect of Electrical Polarization on Electronic Structure in LSM Electrodes: An Operando XAS, RIXS and XES Study. L.Electrochem.Soc. 2017, 164, F3064-F3072.

(60) Lapkowski, M.; Vieil, E. Control of polyaniline electroactivity by ion size exclusion. Svnth. Met. 2000, 109, 199-201.

(61) Combellas, C.; Jiang, D.-E.; Kanoufi, F.; Pinson, J. Podvorica, F. I. Steric Effects in the Reaction of Aryl Radicals on Surfaces. Langmuir 2009, 25, 286-293.

(62) Paulik, M. G.; Brooksby, P. A.; Abell, A. D.; Downard, A. J. Grafting Aryl Diazonium Cations to Polycrystalline Gold: Insights into Film Structure Using Gold Oxide Reduction, Redox Probe Electrochemistry, and Contact Angle Behavior. L Phvs. Chem.C 2007, 111, 78087815. 
(63) Yang, H.-H.; McCreery, R. L. Effects of Surface Monolayers on the Electron-Transfer Kinetics and Adsorption of Methyl Viologen and Phenothiazine Derivatives on Glassy Carbon Electrodes. Anal.Chem. 1999, 71, 4081-4087.

(64) Raicopol, M. D.; Andronescu, C.; Atasiei, R.; Hanganu, A.; Vasile, E.; Brezoiu, A. M.; Pilan, L. Organic layers via aryl diazonium electrochemistry: towards modifying platinum electrodes for interference free glucose biosensors. Electrochimica Acta 2016, 206, 226-237.

TOC graphic

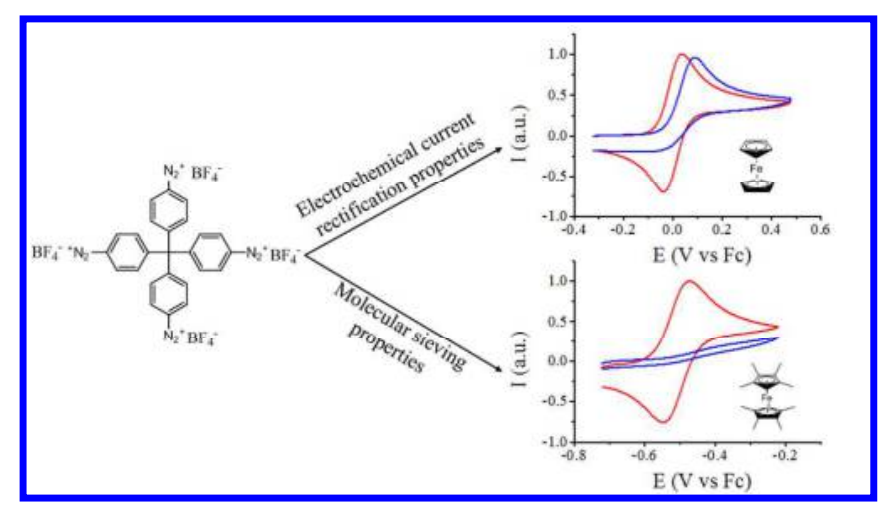

